\title{
A referência e o estereótipo na comunicação colaborativa intercultural
}

\author{
Paola de Carvalho Buvolini Freitas \\ Universidade Estadual Paulista (UNESP) "Júlio de Mesquita Filho", \\ São José do Rio Preto, São Paulo, Brasil \\ paolabuvolini@gmail.com \\ http://orcid.org/0000-0003-3781-7201 \\ Daniela Nogueira de Moraes Garcia \\ Universidade Estadual Paulista "Júlio de Mesquita Filho" (UNESP), \\ Assis, São Paulo, Brasil \\ dany7garcia@gmail.com \\ http://orcid.org/0000-0003-2813-7538
}

DOI: $\underline{\text { http://dx.doi.org/10.21165/el.v47i2.1997 }}$

\begin{abstract}
Resumo
A mediação no teletandem visa discutir, contextualizar acontecimentos linguísticos e culturais das sessões de interação. Trata-se de um espaço propício para o questionamento de dois movimentos: a referência e o estereótipo (LIPPMANN, 2008). Este artigo problematiza, na colaboração intercultural, a recorrência desses na formação de mediadores para não dicotomizar o ensino de línguas estrangeiras, mas vê-lo pelo seu acontecimento. Observamos dois estudos de caso de interações em teletandem para demonstrar a recorrência, via identidade nacional, da referência e do estereótipo e compreender seus usos. Os resultados revelam que as identidades nacionais sobressaem para estabelecer pertencimentos territoriais, expor maior conhecimento deste interagente e entendê-los como processos constitutivos da nacionalidade em confronto, de práticas sociais que tendem a perder a força de sedimentação no diálogo.
\end{abstract}

Palavras-chave: teletandem; estereótipo; referência nacional; mediação.

\section{Reference and stereotype in intercultural collaborative communication}

\begin{abstract}
Teletandem mediation aims at discussing, contextualizing linguistic and cultural issues from the interaction sessions. It is a suitable context for observing two movements: reference and stereotype (LIPPMANN, 2008). This paper focuses on the recurrent appearance of those movements in the mediators education in intercultural collaboration not to dichotomize the teaching of foreign languages but to watch its occurrence. We present two case studies of teletandem interactions in order to analyze and understand the recurrence mentioned through national identities, reference and stereotype. The results show that the national identities stand out to establish territorial belongings, to reveal greater knowledge of this interactant and understand the stereotypes as constitutive processes of nationality.
\end{abstract}

Keywords: teletandem; stereotype; national reference; mediation. 


\section{Introdução}

A proposta do presente artigo é questionar o termo estereótipo no contexto de comunicação intercultural para dimensionar seu uso no espaço do teletandem. A noção de referência aparece como uso de estereótipos que não excluem valores culturais identificáveis como representantes da identidade nacional do país em evidência nas interações do teletandem.

Percebemos que, circundado ao contexto do teletandem, a recorrência do que cunhamos estereótipo esbarra na ideia de referência a fatores culturais e nacionais de um determinado grupo quando não estão enunciados com preconceito e exclusão. Por isso, no âmbito da contemporaneidade e do contexto de comunicação intercultural, as noções de estereótipo e referência podem ser formadoras e/ou indicadoras de identidades nacionais-culturais.

O contexto da comunicação intercultural on-line gerador dos dados do presente artigo é o teletandem vivenciado nos três campi da UNESP que têm o curso de Letras. Este não é um método para aprender línguas, mas um contexto virtual, autônomo e colaborativo no qual pares de falantes de línguas diferentes (nativos ou com proficiência) colaboram para aprender a língua um do outro (TELLES, 2015). Como inicialmente previsto no projeto Teletandem Brasil: línguas estrangeiras para todos (www.teletandembrasil.org), os pares de aprendizes utilizam os recursos de voz, texto e imagens de webcam de aplicativos com tecnologia VOIP (Voice Over Internet Protocol), tais como o Skype. Conversando sobre temas por eles selecionados, esses pares se alternam em períodos relativamente iguais para ajudar um ao outro a aprender suas respectivas línguas nativas ou de proficiência. Hoje, após 11 anos de existência do teletandem, os objetivos se mantêm, mas dialogam fortemente com as culturas que são enunciadas e tematizadas na interação. Por isso, o segundo projeto temático (TELLES, 2011) se intitula Teletandem: Transculturalidade na interação on-line em língua estrangeira pela webcam.

Trazer essa temática para as pesquisas em comunicação intercultural on-line é um passo para compreender os sujeitos envolvidos em participar do movimento de constituição subjetiva e identitária de si mesmo em confronto com outro, estrangeiro estranho em valores, costumes e línguas.

Para a discussão proposta aqui, este artigo se organiza em seções que: a) definem o contexto da pesquisa, ou seja, o teletandem e suas atividades de comunicação intercultural on-line; b) mostram os conceitos teóricos sobre estereótipo e sua possível relação com os processos de sedimentação e pertencimento para o contexto de trocas linguísticas e culturais. A sedimentação e o pertencimento serão tratados vinculados aos estereótipos enunciados nos dados coletados, formando novas seções. Esses conceitos dialogarão com a Teoria da Performatividade de Judith Butler (1990, 2004).

$\mathrm{Na}$ sequência, na seção intitulada "Análise dos dados", traremos excertos de interações que foram transcritas para compreender o uso de estereótipos e mensurar seu valor de referência cultural e nacional para os envolvidos, participantes das interações e, principalmente, para os mediadores que atuam nesse espaço como formadores de opiniões, valores culturais e nacionais. 


\title{
O Teletandem: interação e mediação
}

Evidenciamos o contexto e os objetivos do teletandem que somam educação às novas tecnologias, caracterizando-se como um espaço translinguístico (ZAKIR, 2015) promovedor da comunicação intercultural on-line, pois

\begin{abstract}
Além de ser um projeto pedagógico e social, que visa ao ensino e à transformação das condições sociais de acesso da população economicamente desprivilegiada às línguas e culturas de outros países, o Teletandem Brasil é um projeto de pesquisa. Ele visa (a) ao aprofundamento da compreensão dos modos pelos quais os parceiros de teletandem fazem uso do computador para aprenderem línguas estrangeiras; (b) ao aprofundamento de nossa compreensão sobre a natureza e os processos de interação intercultural no ambiente virtual de teleconferência e (c) às redefinições no papel do professor de línguas estrangeiras ao trabalhar com o teletandem. (TELLES, 2009, p. 69)
\end{abstract}

O teletandem associa a tecnologia a um comunicativismo sociointeracionista, explicado por Telles (2009), que considera o interesse e o nível de profundidade da relação do par interagente, promovendo, a cada um desses aprendizes de línguas estrangeiras, autonomia e crescimento linguístico/cultural e, por isso, constituindo-se em um contexto virtual profícuo para educação/formação mais híbrida ao diferente, com menos categorizações sociais excludentes.

Usar o teletandem e o tandem face a face são formas atualizadas pela tecnologia, no caso do primeiro, e pela mobilidade de receber estrangeiros em universidades do segundo formato, de se aproximar de línguas estrangeiras dentro do espaço acadêmico e do espaço virtual. Através desse contato transcultural on-line, o sujeito se envolve num espaço profícuo para ressignificação dos quesitos: cultura, língua, valores, preconceitos e, no todo, identidades. Portanto, é um espaço de interculturas, interlínguas, intersedimentações e, também, interpelações, uma vez que o teletandem, por si só, é um instrumento de poder. Quem o pratica, frequentemente, pressupõe que postura deve tomar ou é desejada, o que significa ter uma performance diante do outro e do meio online em que estão.

As interações que estudamos neste artigo foram realizadas no espaço do teletandem, em laboratórios das universidades envolvidas (uma brasileira e outra estadunidense). O interagente rompe com o já-estabelecido lugar de aluno e se assume interagente capaz de falar por seu país, inicialmente, como representante nacional. Por essa nova configuração de ensino e aprendizagem na contemporaneidade, os limites de quem aprende e de quem ensina ficam mais equilibrados, mais negociáveis.

A Figura 2 ilustra uma sessão prototípica de teletandem atualmente conduzida na UNESP (campus de Assis). Como podemos observar, a mediação das sessões de teletandem acontece após as interações, com o tempo estipulado de 25/30 minutos para discussão entre os interagentes - alunos das duas línguas estrangeiras envolvidas e o mediador - instrutor de línguas. 
Sessão Prototípica de Teletandem- Interação entre brasileiros e estrangeiros via Skype

Língua I

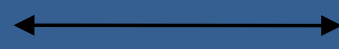

Aproxim. 25 min.
Língua II

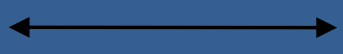

Aproxim. 25 min.

Sessão de Mediação

Aproxim. $30 \mathrm{~min}$.

Figura 2. Sessão prototípica de teletandem (Adaptado de GARCIA, 2013)

O projeto inicial Teletandem: Línguas estrangeiras para todos, de 2006, idealizou interações entre sujeitos de nacionalidades diferentes a fim de propor ensino e aprendizagem de línguas de forma virtual síncrona, por meio da tecnologia trazida pelo Skype e webcam. Com as interações iniciais, depois de convênios feitos entre a universidade brasileira e as internacionais, percebeu-se, através de dados reais feitos por anotações, diários e questionamentos acerca dessa nova modalidade, a necessidade de mediação (da parte do professor de língua estrangeira) do que acontecia nas sessões de interação. Na literatura, Brammerts et al. (2003) utilizam o termo counselling para as ações que, atualmente, desenvolvemos nas sessões de mediação. Difere-se apenas em termos das sessões serem feitas de forma individual ou em grupo. Para os autores, auxiliar os aprendizes a refletir acerca das decisões tomadas e/ou prepará-los para decisões futuras constitui-se objetivo das sessões.

É nesse ambiente, paramentado por webcam, computador, uma sala específica, pelo Skype que, tanto mediadores e interagentes estarão inseridos, evidenciando e, provavelmente, produzindo sujeitos mais fragmentados e mais sedimentados performaticamente via identidade nacional. Fragmentados e sedimentados porque outras identidades nacionais passam a dialogar com as suas, ampliando-as, sufocando-as, comparando-as ou caracterizando-as via sedimentação pelos estereótipos.

Nesse jogo de troca - intercâmbio on-line, com comunicação síncrona, cabe pensar o que é falado pelo par. A fim de acompanhar o processo e a aprendizagem das línguas, após a interação acontece a mediação, espaço para a discussão do que foi abordado, evidenciado, comparado entre os participantes do teletandem também conhecidos por interagentes, mediado por um professor ou aluno de pós-graduação e graduação da instituição.

As vivências nas interações, nas mediações e nas pesquisas acerca do teletandem são fomentadoras da relação de ensino e aprendizagem críticas no contexto intercultural on-line e da constituição do sujeito a partir da fala do outro. Por isso, as questões seguintes mostram inquietações relevantes desse contexto e nos impulsionam na condução do presente estudo. Na interação com o outro, a fala que demonstra sensocomum, generalizações e estereótipo é uma referência positiva ou negativa para a comunicação intercultural? Por que é recorrente o uso de estereótipos nas interações iniciais ou mesmo quando discutimos a língua e cultura estrangeiras? Como discutir, no 
teletandem, questões de futebol para brasileiros e de fast food para os estadunidenses, canadenses, especificamente? Essa visão estereotipada da nacionalidade expressa pelos aprendizes de teletandem é parte da performance de um sujeito híbrido ou uma faceta de segurança para não ser avaliado negativamente?

Por essas constantes é que percebemos que o uso do estereótipo pode ser uma referência à identidade nacional do interagente que assim o faz para poder representar sua nação no teletandem, especificamente.

\section{O estereótipo}

Water Lippmann, escritor e comentarista político estadunidense, foi um dos primeiros a nomear estereótipo. Ele buscou compreender, ancorado na Psicologia Moderna, como os indivíduos representavam a realidade social na qual estavam inseridos, o que rechaçavam e o que absorviam como certo diante da cultura da realidade social da qual pertenciam ou desejavam pertencer. Com esse olhar, Lippman (2008) define estereótipo como imagens mentais que auxiliam os indivíduos a lidar com a realidade que os cerca. Segundo Cabecinhas (2004), seu uso, em 1798, representava uma chapa de metal para reproduzir textos nas tipografias. Por isso, é fácil fazer a correlação da definição com a etimologia do termo, stereòs, em grego, significa rígido e túpos, impressão. Portanto, uma impressão rígida, em nível subjetivo, das relações que o indivíduo constrói, organiza, visualiza da sociedade em que vive.

Baccega (1998, p. 8) traz considerações importantes de Lippmann para a definição de estereótipo.

Segundo Lippmann (2008), quando nos aproximamos da realidade, "não vemos primeiro para depois definir, mas primeiro definimos e depois vemos. Aí está o estereótipo: são os tipos aceitos, os padrões correntes, as versões padronizadas". Eles interferem na nossa percepção da realidade, levando-nos a "ver" de um modo préconstruído pela cultura e transmitido pela linguagem.

Para Mazzara (1999, p. 14),

Os estereótipos formam parte da cultura de um grupo e, como tais, são adquiridos pelos indivíduos e utilizados para uma eficaz compreensão da realidade. Ademais, a conscientização dos estereótipos cumpre para o indivíduo uma função de tipo defensivo: ao contribuir com o mantimento de uma cultura e de determinadas formas de organização social, garantem o resguardo das posições alcançadas.

Ver o estereótipo como parte da cultura é recorrente, mas acreditar na sua eficácia para a compreensão da realidade na qual ele habita leva seu conteúdo à sedimentação como um dado, uma informação posta, certa, rígida e, consequentemente, excludente e preconceituosa, como entende Baccega (1998, p. 10):

O estereótipo, assim como o conceito, é um reflexo/refração específica da realidade ou seja, reflete com desvios, como um lápis que, colocado em um copo de água, "entorta", mas o estereótipo comporta uma carga adicional do fator subjetivo, que se manifesta sob a forma de elementos emocionais, valorativos e volitivos, que vão influenciar o comportamento humano. Ele se manifesta, portanto, em bases emocionais, 
trazendo em si, como já dissemos, juízos de valor preconcebidos, preconceitos, e atuam na nossa vontade.

Ter o estereótipo como algo posto de determinada comunidade é inverter seu estado de pressuposto, criado pelo povo e reiterado, performaticamente, pelo povo, subjetivamente, para o estado de posto, sedimentado. Regra a ser seguida para manter a sensação de nação, de grupo, de pertencimento. Mas, em tempos de quebra de fronteiras e contínuos fluxos realizados pela globalização, há uma questão chamativa: por que os estereótipos não diluíram ou acabaram? Possivelmente, pela necessidade de pertencimento diante da liquidez moderna, como salientou Bauman (2005).

Analisaremos, neste trabalho, a recorrência de questões culturais com foco no estereótipo e/ou referência cultural em dados gerados a partir de interações de teletandem ocorridas em 2012. Os dados analisados foram transcritos via verbatim e os nomes dos interagentes alterados.

Abaixo segue o primeiro excerto que analisaremos como amostra da interação entre um brasileiro, Tiago, e um cubano, Ricardo, que mora nos Estados Unidos e estuda na universidade estadunidense parceira do Teletandem.

Esse primeiro excerto é posto aqui para evidenciar a noção de estereótipo apresentada na interação com as definições que encontramos nos referenciais teóricos sobre $\mathrm{o}$ assunto.

Ricardo: Você perguntou: o que tenho visto do Brasil aqui?

Tiago: Hã. Hã.

Ricardo: Outro pais, visto coisas boas, eu ah, [...] agora o Brasil está no, ah, no momento histórico muito importante, para o país e para a projeção do país no âmbito internacional.

Tiago: sim

Ricardo: Então, ah, seu eu falar isso do Brasil, ah, o crescimento econômico, o desenvolvimento, que o país emergente no contexto global, isso que se ouve mais do Brasil agora nos Estados Unidos, especialmente para os estudantes da América Latina.

Tiago: Entendi

Ricardo: Isto muitas pessoas estão aprendendo. Mas também se fala muito em etanol, e a Indústria do etanol, e o combustivel do Brasil, e eu acho o crescimento econômico, econômico que tenha fazido o Brasil (incompreensivel) então o Brasil foi o ultimo país que entrou na restrição e o primeiro que saiu. Então isto é questão do papel que está tendo o Brasil no novo mundo, eu acho, o mundo onde estão existindo países emergentes, países... como Índia, China, ... E agora nos Estados Unidos quando se fala do Brasil se fala de coisas positivas. A parte dos estereótipos das garotas boas, das praias do Rio, isso ao nível do americano comum, do americano da rua.

Tiago: Hã, hã

Excerto 1 - Fonte: Inter 4, 2012.

Ao comparar Brasil e Estados Unidos, Ricardo pontua, no aqui e agora de sua fala, características geográficas e estéticas, partes da dimensão cultural do Brasil, comuns, padronizadas porque são e foram imagens mentais construídas por alguém que tinha o poder de construir determinadas "verdades" nacionais. Como dito por Lippmann 
(2008) no início dessa seção, o estereótipo como imagens mentais auxilia a enxergar uma realidade para poder falar dela e com quem pertence a ela, por isso, são recorrentes no espaço do teletandem, já que este pede que duas nacionalidades estejam frente a frente on-line para conversação com fins pedagógicos.

Portanto, confirmamos a grandeza da área da comunicação intercultural com as palavras de ElHajji (2005, p. 55):

Neste sentido, a CIC (Comunicação Intercultural) tem um duplo valor socio-científico. Além de servir de interface social intercomunitária, ela constitui um quadro epistêmico capaz de efetivar as condições teóricas e analíticas necessárias para a apreensão do significado dos fluxos migratórios a partir de seus rastros comunicativos. Enquanto horizonte epistemológico, a CIC pode oferecer um plano reflexivo altamente operacional, seguro e confiável para manobras teóricas inéditas e audaciosas, capazes de trilhar profundamente a complexidade sociopolítica da época contemporânea e retraçar de modo bastante fiel o emaranhado geocultural da era global.

No horizonte epistemológico da comunicação intercultural, também, on-line, a complexidade sociopolítica e subjetiva dos participantes representantes de seus países pede um plano reflexivo muito crítico e respeitoso para não gerar sedimentações em termos de estereótipos excludentes e preconceituosos impedidores do fluxo global e cultural acontecer com mérito e equidade. Esse plano reflexivo é função específica do mediador de teletandem que discute situações enunciadas nas interações a fim de construir noções linguísticas e culturais respeitosas nas suas diferenças e formadoras de sujeitos híbridos pelo contato com o outro estrangeiro.

\section{A permanência do estereótipo pela sedimentação}

O termo sedimentação será aqui explicado como indício deflagrador dos estereótipos como referências culturais.

A fala do sujeito que participa das interações de teletandem, nomeado de interagentes, como usaremos, é nosso foco porque mostrará como está interpelada ou não de estereótipos. É notório perceber que, ao tratar de estereótipos, trabalhamos com a noção de valor (negativo e positivo) para dimensionar a cultura. Assim, também, ressaltamos que o foco inicial está na dimensão de estereótipos sociais que tratam da cultura.

Como os interagentes são de nacionalidades diferentes, a identidade nacional tende, fortemente, a ser usada como forma de perceber os movimentos de interação dos envolvidos. A identidade nacional é comparada e confrontada, de modo implícito ou explícito, no discurso do interagente de língua estrangeira, para tachar assuntos que são específicos para cada sujeito e para cada lugar. Mas, o primeiro choque é que, da comparação ou marcação de diferenças (WOODWARD, 2013; TELLES, 2015) na interação em teletandem, saem dois movimentos performativos: ora os pares evidenciam um pertencimento, ora eles deslocam estereótipos construindo outros valores culturais, reformulando o que estava pertencente neles como visto no excerto acima e explicitado no recorte abaixo com a fala de Ricardo, interagente que nasceu em Cuba, mas mora há anos nos Estados Unidos. 
Brasil emergente economicamente para o americano leitor, intelectualizado deslocamento de valor porque o Brasil não é visto por ele como subdesenvolvido e/ou marginalizado pela primeira potência, mas sim visto positivamente, com crescimento econômico em detrimento da visão, inclusive materializada pelo termo estereótipo, de um país com garotas boas, das praias do Rio (vide excerto 1).

Para explicar termos específicos que adotaremos neste artigo, tais como sedimentação, performatividade, subjetividade, alinhavamos teorias as quais podem explicar (e parecem fazer isso com maestria) nossa atenção. Essas teorias são a Teoria da performatividade (BUTLER, 1991, 2004) e os Estudos Culturais (HALL, 2006; SILVA, 2011) somados às Teorias da Informação e Comunicação (TICs).

Para a compreensão maior de estereótipo, olhamos para a dimensão subjetiva do sujeito que, perpassado pela globalização e pela tecnologia nesse contexto intercultural, enuncia como representante nacional de uma sociedade, ou seja, enuncia valores sociais. Para a dimensão de sujeito, buscamos os trabalhos de Rolnik (1997).

Da leitura de Rolnik (1997), percebemos como os estudos se intercruzam. Para isso, citamos um trecho de seu texto "Toxicômanos de identidade. Subjetividade em tempo de globalização" do livro Cultura e subjetividade. Saberes Nômades (ROLNIK, 1997, p. 19):

A mesma globalização que intensifica as misturas e pulveriza as identidades implica também na produção de kits de perfis-padrão de acordo com cada órbita do mercado para serem consumidos pelas subjetividades, independemente do contexto geográfico, nacional, cultural.

Silva (2013), em Identidade e diferença, afirma que quem participa da fragmentação de identidades de forma consciente também reconstrói identidades históricas, herdadas de um suposto passado comum. Associamos tal processo de reconstrução ao conceito de sedimentação que Butler (2004) nos traz. É esse passado comum que dissemina valores, atitudes e, muitas vezes, leva a uma fala superficial por meio da performatividade e a estereótipos, processo de sedimentar o que é mais denso. E, por isso, categorizar, classificar, dicotomizar e excluir, definindo estereótipo como preconceito, como uma referência social com valor negativo.

No artigo de Luciana Parisi (2009), As aventuras do sexo [The adventure of a sex], há uma clara definição da performatividade de Butler. Para Parisi, a performatividade não é nem intencional nem apenas arbitrária. A historicidade específica de discursos determina seu poder de transformar em atos o que os discursos nomeiam. Exemplo dessa prática é o discurso em torno do nascimento de uma menina. Compra-se um enxoval todo nos tons de amarelo, rosa e, repetidas vezes, ouve-se e falase sobre o que ela precisa ter: brinco, pulseira, enfeites no cabelo. Distinção estabelecida discursivamente do menino.

É essa repetição de falas e sinais dentro de uma grade de poder que determina posições sociais dentro, também, de suas restrições ideológico-sociais. Este movimento leva a uma normalização e, consequentemente, sedimentação carregada no processo de crescimento dessa menina, como no exemplo. 
Derrida (1991) esclarece que, nesse jogo identidade $x$ diferença, o poder tem função primordial. É por ele que os sujeitos se sentem pertencentes ou não a determinados grupos e ambientes. $\mathrm{O}$ processo de sentir-se pertencendo a uma identidade se dá pela possibilidade de repetição de um ato linguístico. Essa repetibilidade da linguagem com mudanças de sentido, seja pela fala ou pela escrita, nomeia o que Derrida chamou de iterabilidade. Tal pertencimento identitário se dá pelo processo de citacionalidade, movimento de citar palavras em outros contextos, como se recortássemos e colássemos uma expressão em diversos contextos, igual a citação.

Ele diz que "quem tem o poder de representar tem o poder de definir e determinar a identidade" (SILVA, 2013, p. 91). É essa repetição de falas e sinais dentro de uma grade de poder que determina posições sociais dentro, inclusive, de suas restrições ideológico-sociais e que dialoga com o que Lippmann (2008) trouxe acerca de estereótipos. Esse movimento leva a uma normalização e, consequentemente, sedimentação de valores e culturas manifestados na e pela língua na interação.

A nosso ver, aqui, entram em jogo os processos de citacionalidade e iterabilidade como formas de sedimentação de discursos que interpelam seus usuários.

Para a maior compreensão desses processos, trazemos a figura a seguir (que elaboramos para esse espaço), ilustrativa do processo químico de sedimentação, feito em laboratório, com a finalidade de separar elementos sólidos de outros menos sólidos. Para a interpretação das noções trazidas de Derrida (1991), os elementos são os valores ditados pela sociedade via linguagem (Performatividade). Portanto, o que fica no fundo são os valores mais fortes, mais duros de quebrar, os possíveis estereótipos ou referências. O que flutua fica mais próximo da superfície, mais fácil de se misturar com ar e outros elementos: são as expectativas híbridas de novos conhecimentos. Os copos podem indicar os sujeitos. No seu processo de desenvolvimento, recebem muitos conhecimentos - as bolhas da figura abaixo, e durante esse processo, sedimentam o que é valor indissolúvel, fortemente constitutivo de dada sociedade pelo processo cunhado por Butler (2004) de performatividade.

O problema é que, ao mesmo tempo, esses valores fazem pertencer e excluir a nível de nação, reforçando a necessidade deste estudo para a prática humanizadora e respeitável do contato com outras nações. A discussão dessa problemática ou complexidade vivida pelo contato intercultural on-line do teletandem precisa ser acionada e questionada no momento da mediação, o que poderá garantir uma formação com maior amplitude cultural e humana para mediador e interagentes.

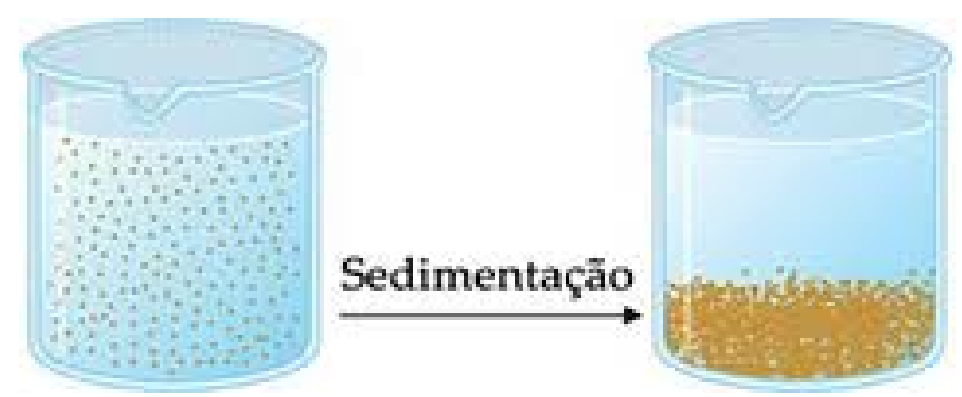

Figura 1. Ilustração do processo de sedimentação 
É com esse aparato teórico que vislumbraremos, abaixo, os dados dos pares em interações de teletandem. A troca de turnos feita por sujeitos que, a todo momento, têm uma performance diante, inicialmente, de um outro que constitui um lugar de poder, por isso, também uma posição específica de sujeito. É nesta posição de interagente e estrangeiro que as performances surgem para fabricar novas identidades. E todo este processo, bastante antropofágico, envolve, desloca e reformula identidades.

\section{Análise dos casos}

Segundo Gilhan (2000), o estudo de caso aborda um contexto específico de pesquisa com participantes também específicos.

Assim, epistemológica e metodologicamente, este artigo se encontra mais apoiado na teoria crítica, uma vez que ela é transnacional e subjetiva, vê os envolvidos na pesquisa de forma interativa e, é por meio desta, que o que pode ser conhecido fica evidente. Salientamos que a visão crítica de sujeitos que se colocam na função de interagentes passa por relações de poder construídas no espaço em que vivenciam as interações. Ele tem o poder de decidir, mesmo que reciprocamente, o que falar e como falar, além de sua constituição subjetiva de poder, refletindo questões linguísticas, culturais que, por esse mecanismo de reflexão, proporcionam compreender sua posição de sujeito em relação a outros que o rodeiam.

Especificando, os participantes estrangeiros e brasileiros têm idades entre 18 a 22 anos. $\mathrm{O}$ interagente estrangeiro do primeiro caso cursava Relações Internacionais em uma Universidade particular de Washington e o brasileiro, Letras, em uma universidade pública do interior de São Paulo. Os interagentes do segundo caso cursavam, respectivamente, Administração em uma universidade particular dos Estados Unidos e Letras na universidade brasileira.

Usamos, para a análise dos casos, somente as interações em português e falas transcritas. A indicação de fonte ao fim de cada trecho selecionado indica em qual interação a temática foi enunciada. Para o primeiro estudo de caso, usamos 4 interações e, no segundo, 5 interações. Os participantes dividiam o tempo total da interação para praticarem as línguas portuguesa e inglesa.

O primeiro estudo de caso é formado por Tiago e Ricardo (nomes fictícios). Tiago é o brasileiro e Ricardo, cubano, morador dos Estados Unidos. Trazemos excertos da metade da interação que acontecia em português que toca nas questões culturais, reveladoras da qualidade dos estereótipos e da identidade nacional do país em questão, Brasil. Ressaltamos que só analisamos excertos da conversa em português para mensurar e compreender os estereótipos e as referências da nacionalidade brasileira.

O primeiro excerto exposto acima mostra a conversa entre Tiago e Ricardo sobre a economia brasileira, com o olhar de um estrangeiro que vê o crescimento do etanol, de um Brasil emergente. Ricardo, o estrangeiro, consegue identificar bem quem fala da mesma forma que ele, de dentro da academia e de estudos específicos da América Latina. Ele salienta com ênfase que sua visão de "brasilidade" está interpelada pelos jornais que lê e os estudos que desenvolve na universidade, a partir do curso de Relações Internacionais, que pode remeter a sua origem latina. 
A sensação de não marcação de estereótipos nacionais trazida por Ricardo se dá pela falta de iterabilidade e citacionalidade, processos identificados por Derrida (1991) e usados por Butler no fazer performativo. Ou seja, Ricardo não repete (iterabilidade) uma grade regulatória para ser identificado como americano ou latino, nem cita (citacionalidade) enunciados padronizados e rígidos a respeito do Brasil como são cunhados os estereótipos. Ricardo não repete e/ou cita o que está marcado nas ruas e na sociedade como senso comum, ele não recorre ao mesmo discurso da massa, ao já-dito que promove mais e mais sedimentações e, consequentes, estereótipos excludentes. Ele ressalta o que é positivo no Brasil agora, como visto em sua última fala no excerto acima: "E agora nos Estados Unidos quando se fala do Brasil se fala de coisas positivas".

$\mathrm{Na}$ sequência da interação entre Tiago e Ricardo, o excerto 2 evidencia o estereótipo do brasileiro pouco culto e político enunciado pelo próprio brasileiro no jogo comparativo e formativo da interação do teletandem.

Ricardo: então, eu... Eu gosto muito do Brasil. Eu acho que agora Brasil está co... num momento muito essencial da sua história.

Tiago: Tá mesmo. Esta num momento de transição.

Ricardo: E... e as projeções do poder do Brasil no mundo são... são muito interessante. Uma potência emergente bastante poderosa. E não sei o que os brasileiros diz sobre isso, não sei o que os brasileiros opinião sobre esso, isso, mas ahm...Isso é a percepção afora do Brasil. Não sei qual é a percepção dentro do Brasil. O que você acha?

Tiago: Olha. Brasileiro é um povo mais ingrato. A gente sabe que o país tá crescendo, tá emergente, principalmente depois do governo Lula, que você deve conhecer. E... O Brasil teve uma exposição internacional pra fora do Brasil. E... Aqui, a massa intelectual do país, a massa universitária, o pessoal que estudou, o pessoal que conhece um pouco de economia e de política, aqui no Brasil, concorda que o Brasil é uma próxima, próxima potencia, uma possível próxima potencia. Mas a maioria do povão aqui. O Brasil ainda não é um país muito alfabetizado, assim, o pessoal não se interessa muito por cultura, por arte, por política, são poucas as pessoas que se interessam, então. Mas as que se interessam concordam com esse ponto de vista que você é o povão aqui é meio ingrato.

\section{Excerto 2 - Fonte: Inter 1, 2012}

É interessante perceber que Ricardo, cubano que mora nos Estados Unidos, não sabe a opinião dos brasileiros sobre a economia do Brasil, ou seja, a economia não foi estereotipada a ponto de se tornar uma performance repetida e fazer saber sua informação. Ele pretende descobrir o que pensam. E usa o termo "acho" da fala "Ricardo: então, eu... Eu gosto muito do Brasil. Eu acho que agora Brasil está co... num momento muito essencial da sua história" como forma dessa autonomia individual, é seu saber, sua visão. Talvez essa forma interpele menos que a forma imperativa de outras expressões como "Goste/gostem do Brasil".

A fala de Tiago, o interagente brasileiro, na busca por responder como cidadão brasileiro, ou seja, metonimicamente, vê a economia através de sua interpelação. Ele usa o "a gente" provavelmente por estar interpelado socialmente; essa expressão "a gente" parece o coletivo de um grupo nacionalmente homogêneo e carregado de poder. Nota-se a iterabilidade para valorizar o conhecimento eloquente do par com o início da fala de Tiago, "A gente sabe que o país está crescendo, tá emergente”. 
No entanto, mais ao final de sua fala comparativa em termos dicotômicos (massa intelectual x povão; quem se interessa por economia x quem não se interessa; Brasil emergente x Brasil não muito alfabetizado), Tiago usa a adversativa mas com o tom de quem vive nas "terras tupiniquins" e pode afirmar pelo contraste que o povão é ingrato e não muito alfabetizado, por isso, a visão diferente de Ricardo e positiva a respeito do Brasil economicamente emergente pediu ao brasileiro uma contextualização social que esbarrou no uso de estereótipos. Essa performance do interagente brasileiro pode sedimentar as ideias de Ricardo, o estrangeiro, interpelando-o a ver o Brasil como um povo não muito alfabetizado, por isso, ingrato econômica, política e socialmente.

$\mathrm{Na}$ sequência dos excertos selecionados, trazemos a segunda parceria formada por Beatriz (brasileira) e Jeremy (estadunidense). Na quarta interação deles, há um momento destinado a falar sobre shopping e os estereótipos sedimentados por ambos a respeito do que esse espaço comercial suscita.

Jeremy: as mulheres gostam de entrar no shopping e experimentar, colocar todas as roupas

Beatriz: É, todos os sapatos. Eu sou assim também. Peço todos pro vendedor e so levo um.

Jeremy: E eu falei para elas que quando eu entro, os homens são diferentes

Beatriz: É, entra numa loja pra comprar

Jeremy: Sim, já sabe tudo o que ve quer comprar

Beatriz: É, agora mulher não, gosta de ver e experimentar

Jeremy: é, eu fico zuando um pouco, depois eu fico no shopping por muito tempo, fico nervoso, quero sair bem rápido.

Beatriz: ve não gosta? Nossa, eu adoro. Se precisar passar uma tarde toda, eu passo numa boa.

Jeremy: dor de cabeça, eu tenho dor de cabeça grande dentro do shopping

Beatriz: enxaqueca. Ou so de vez em quando que da dor de cabeça, quando tá dentro do shopping

Jeremy: Muitas pessoas correndo, bem rápido, muitas coisas eu so quero comer e sair bem rápido

Beatriz: Ah não eu gosto de comer, de ficar andando, eu gosto muito de Mc, McDonalds

Jeremy: ah tá

\section{Excerto 4- Fonte: Inter 4, 2012}

Neste momento, os aspectos interativos vivenciados nas interações são suscitados para não ser uma simples descrição das interações. O mediador pede que o interagente conte como foi a interação, o que causou estranhamento ou aproximações. A partir do relato do participante, o mediador deve estar equipado criticamente para não só ouvir um relato de experiências, perpetuação de estereótipos como enquadrado pelo senso-comum, com tom excludente e concepção sedimentada do outro, como salientou Telles (2015). É exatamente na mediação que as possibilidades e o potencial para promoção de ensino e aprendizagem de línguas crítico se constróem e se realizam no diálogo. Por isso, o mediador precisa ouvir com atenção e questionar possíveis situações para fazer pensar como definimos, (re)construímos a imagem que temos e/ou teremos do parceiro. 
A visão de Jeremy sobre a ida e a atividade nos shoppings para, especificamente, as mulheres é distinta de seu par, também uma mulher, mas brasileira. Nesse momento, eles precisam falar representando todo o país porque isso traz a marcação da diferença - aqui é assim e aí, diferente (WOODWARD, 2013).

Beatriz se mostra surpresa quando Jeremy começa a dizer que não gosta de passar muito tempo no shopping, isso lhe dá dor de cabeça. Para ela, tal fala desconstrói a ideia imaginada de que, importado dos EUA, os shoppings não são tão interessantes para passar horas e horas.

Woodward (2013), no capítulo primeiro do livro Identidade e diferença, explicita que a diferença entre as diversas identidades nacionais reside, portanto, nas diferentes formas pelas quais elas são imaginadas. Fica claro o espanto, mais do que a surpresa, indicando uma identidade estadunidense imaginada por ela. Ele, morador dos EUA, amaria os shoppings. Imagem que é definida por estereótipo e pode servir como uma referência à cultura dos shoppings e fast foods estadunidenses.

A identidade imaginada é quebrada e justificada, ele não gosta de ficar muito no shopping porque tem muita gente e vai com um propósito estabelecido, comer ou comprar algo determinado. Por isso, performaticamente, se coloca como um sujeito não estereotipado.

Neste excerto, Jeremy e Beatriz são analisados como sujeitos numa processualidade, segundo as ideias de Rolnik (1997) que não se estabiliza de maneira definitiva, porque ora é eu ora é nós no discurso de pertencimento social e nacional que já se apresenta mais diluído pela globalização.

\section{Considerações finais}

Pensando a constituição do sujeito, podemos rever, ressignificar nossa performance docente por meio da mediação de teletandem, cuidando para que nossa fala reiterada de professor-mediador valorize a diferença, torne o estereótipo uma referência a ser observada, discutida e não, essencial e supercialmente, sedimentada pela exclusão. Acreditamos, ainda, que o estereótipo possa ser utilizado como instrumento linguístico e identificador da comunicação intercultural no que concerne à identidade nacional-cultural.

Através da análise das interações, percebemos que os interagentes, dentro de suas perspectivas ideológicas, apresentam suas identidades nacionais. Eles, de formas diferentes, evidenciam traços de suas nacionalidades por signos sociais e mostram o quanto estão sedimentados ao nacional ou mais globalizados. A percepção da sedimentação se dá pelo uso da iterabilidade e da citacionalidade do já dito, do comum, do estereotipado, o que possibilita problematizar o uso do estereótipo.

Por isso, parece profícuo, para o campo da Comunicação Intercultural, desbravar as ciências sociais que dialogam, felizmente, com a Linguística Aplicada, sustentando a necessidade de professores de línguas estrangeiras e, principalmente, mediadores do teletandem de desnaturalizar estereótipos e ver, na mediação, cada caso de sedimentação cultural e nacional (a pensar no contexto do teletandem, o qual possibilita o uso das línguas para falar sobre as culturas das línguas em interação) com o cuidado do mediador de marcar a diferença como característica nacional a somar, hibridizar 
sujeitos líquidos, não aprisioná-los com e por impressões rígidas, consequentemente, excludentes.

Tomar a teoria da performatividade para ver tais interagentes é vê-los na ruptura da norma, da normatividade, do estereotipado. É a possibilidade de vê-los diferentes também, desconstruindo imagens idealizadas de interagentes, brasileiros e estrangeiros. As identificações entre eles promovem nossa identificação com eles como mediadores, processo que incita reflexão e crítica na formação docente e no estabelecimento de interações fecundas que vão do nacional ao singular.

Preocupados com a educação, com a formação de professores de línguas, a temática deste artigo procurou mostrar o uso de estereótipos nas interações do teletandem a fim de ampliar o ensino e a aprendizagem de línguas nesse contexto, tornando-os singulares e humanos a partir de discussões culturais não sedimentadas em valores culturais excludentes e metonímicos.

\section{REFERÊNCIAS}

BACCEGA, M. A. Comunicação e Linguagem: discursos e ciência. São Paulo: Moderna, 1998.

BAUMAN, Z. Identidade: entrevista a Benedetto Vecchi. Tradução de Carlos Alberto Medeiros. Rio de Janeiro: Jorge Zahar, 2005.

BRAMMERTS, H.; CALVERT, M.; KLEPPIN, K. Aims and approaches in individual learner counselling. In: LEWIS, T.; WALKER, L. (Eds.). Autonomous Language Learning In-Tandem. Sheffield, UK: Academy Electronic Publications, 2013. p. 105114.

BUTLER, J. Gender Trouble: Feminism and the Subversion of Identity. New York: Routledge, 1990.

Lenguaje, poder e identidad. Tradução de Javier Sáez y Beatriz Preciado. Madrid: Editora Síntesis, 2004.

CABECINHAS, R. Processos cognitivos, cultura e estereótipos sociais. In: ACTAS DO II CONGRESSO IBÉRICO DE CIÊNCIAS DA COMUNICAÇÃO, 2004, Universidade da Beira Interior, Covilhã. Disponível em: $<$ http://hdl.handle.net/1822/1650>. Acesso em: 29 maio 2017. p. 3-18.

DERRIDA, J. Limited Inc. Campinas: Papirus, 1991.

ELHAJJI, M. Comunicação Intercultural: apontamentos analíticos. Revista Contemporânea, UERJ, n. 4, n. 1, p. 52-59, 2005.

GARCIA, D. N. M. O que os pares de Teletandem (não) negociam. São Paulo: UNESP, 2013.

GILHAN, B. Case Study Research Methods. London: Continuun, 2000.

HALL, S. A identidade cultural na pós-modernidade. Tradução de Tomaz Tadeu da Silva e Guacira Lopes Louro. 11. ed. Rio de Janeiro: DP\&A, 2006.

LIPPMANN, W. Opinião pública. Petrópolis: Vozes, 2008.

MAZZARA, B. M. Estereotipos y prejuicios. Madrid: Acento Editorial, 1999. 
PARISI, L. The Adventures of a Sex. In: Deleuze and Queer Theory. Edited by Chrysanthi Nigianni and Merl Storr. Edinburgh University Press, 2009. p. 72-91.

ROLNIK, S. Toxicômanos de identidade: subjetividade em tempo de globalização. Cultura e subjetividade: saberes nômades. Campinas: Papirus, 1997. p. 19-24.

SILVA, T. T. Identidade e diferença. A perspectiva dos Estudos Culturais. 13. ed. Petrópolis: Vozes, 2013.

TELlES, J. A. Teletandem and Performativity. Revista Brasileira de Linguística Aplicada, Belo Horizonte, v. 15, n. 1, p. 1-30, 2015. Teletandem: um contexto virtual, autônomo e colaborativo para aprendizagem de línguas estrangeiras no século XXI. Campinas: Pontes, 2009.

Projeto Teletandem Brasil: Línguas Estrangeiras para Todos - Ensinando e Aprendendo línguas estrangeiras in-tandem via MSN Messenger. Faculdade de Ciências e Letras de Assis, UNESP. 2006. Disponível em:

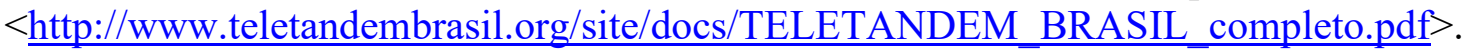
Acesso em: 02 jul. 2014.

VYGOTSKY, L. A formação social da mente: o desenvolvimento dos processos psicológicos superiores. Tradução de José Cipolla Neto, Luís Silveira Menna Barreto, Solange Castro Afeche. 7. ed. São Paulo: Martins Fontes, 2007.

WOODWARD, K. Identidade e diferença: uma introdução teórica e conceitual. In: SILVA, T. T. da (Org.). Identidade e Diferença: a perspectiva dos estudos culturais. Petrópolis: Vozes, 2013. p. 7-72.

ZAKIR, M. A. Cultura e $(m)$ telecolaboração: uma análise de parcerias de teletandem institucional. 2015. 234 f. Tese (Doutorado em Estudos Linguísticos) - Instituto de Biociências, Letras e Ciências Exatas, Universidade Estadual Paulista, São José do Rio Preto, 2015.

Recebido em: 22/09/2017

Aprovado em: 07/08/2018 